Syntax Fusion : Jurnal Nasional Indonesia

p-ISSN: -

e-ISSN : 2775-4440

Vol. 1, No. 7, Juli 2021

\title{
ANALISIS KUALITAS PELAYANAN TERHADAP KEPUASAN PELANGGAN DENGAN MENGGUNAKAN METODE CSI DAN IPA
}

\author{
Sujik Nor Afandi, Akhmad Suharto, dan Jekti Rahayu \\ Universitas Muhammadiyah Jember, Indonesia \\ Email: sujinorafandi@gmail.com, akhmadsuharto@unmuhjember.ac.id, \\ Jektirahayu@unmuhjember.ac.id
}

\begin{abstract}
Abstrak
Tujuan dari penelitian ini untuk mengukur tingkat kepuasan pelanggan terhadap kualitas pelayanan Afc Futsal Center di Tegaldlimo, Banyuwangi. Metode analisis data yang digunakan adalah analisis deskriptif Kuantitatif, (Customer Satisfaction Index) CSI, (Importance Performance Analisis) IPA. Sempel yang digunakan dalam penelitian ini adalah sebanyak 89 responde, jenis data yang digunakan adalah penyebaran Kuisioner dan Observasi. Sedangkan didalanya menggunakan tingkat kinerja serta harapan/kepentingan.hasil penelitian ini menunjukkan bahwa sebagian besar responden yang merupakan pelanggan Afc Futsal Center dapat dikatakan Cukup Puas, hal ini terlihat dari hasil pengukuran CSI sebanyak 58,32\%. Sedangkan dalam pengukuran IPA ada 3 atribut yang menjadi prioritas utama dimana atribut ini di anggap penting bagi pelanggan namun kinerja nya masih kurang baik atribut tersebut antara lain kesigapan karyawan dalam melayani bokingan serta pesanan lapangan untuk bermain, kecepatan karyawan pada Afc Futsal Center dalam mengatasi keluhan dari pelanggan, keramahan karyawan terhadap pelanggan yang ada ditempat penyewaan lapangan futsal.
\end{abstract}

Kata Kunci; Kualitas Pelayanan, CSI, IPA

\section{Pendahuluan}

Olahraga futsal banyak di senangi dan digemari di kalangan pencinta olahraga futsal baik dari lingkungan sekolah SMP, SMA serta lingkungan masyarakat seperti halnya dikalangan anak muda baik laki - laki dan perempuan serta orang tua yang mempunyai hoby serta bakat dalam permainan futsal, dan penyewaan lapangan futsal pun menjadi alternatif untuk menyalurkan suatu hoby serta bakat mereka dalam berolahraga dengan situasi yang ada sekarang ini, pengusaha akan berlomba lomba dalam memperbaiki usaha mereka, salah 
satunya adalah Afc Futsal Center yang berletak di kecamatan Tegaldlimo, banyuwangi dimana para pelaku bisnis dituntut untuk berorientasi pada kepuasan pelanggan sebagai tujuan utamanya, dikarenakan kepuasan pelanggan merupakan hal yang penting dalam menjalankan serta menunjang suatu usaha penyewaan lapangan futsal

Kunci utama untuk menghasikan suatu kepuasaan pelanggan adalah dengan memberikan nilai dan kepuasan kepada pelanggan melalui penyampaian produk atau jasa yang berkualitas dimana perusahaan harus memberikan kualitas pelayanan yang dapat memuaskan para pelanggan dimana jika pelanggan tidak diberikan suatu pelayanan dengan baik maka mereka akan meninggalkan perusahaan dan akan menjadi pelanggan kompetitior yang akan mengakibatkan suatu penurunan penjualan dan akhirnya akan mengalami suatu kerugian. Kualitas pelayanan yang diterima biasa disebut dengan service quality (SERQUAL) adalah seberapa jauh perbedaan antara harapan dan kenyataan para pelanggan atas pelayanan yang mereka terima selama ini dan banyak dijadikan acuan, yang dikembangkan oleh Parasuraman, Zeithmal dan Berry terdapat lima service quality menurut Parasuraman, et al., dalam Tjiptono (2011: 347) antara lain tangible, reability, responsivenes, assurance, empathy.

Kualitas pelayanan merupakan keseluruhan dari ciri dari suatu barang serta jasa yang bisa mempengaruhi kemampuan untuk memenuhi kebutuhan dari pelanggan Kotler (2012), Suatu produk atau jasa dapat memuaskan pelanggan dengan memenuhi suatu kebutuhan dari pelanggan tersebut serta keingianan nya terpenuhi pada saat menyewa lapangan futsal, dengan demikian kualitas pelayanan dipengaruhi oleh dua factor yaitu customer expectation (harapan pelanggan) dan customer perceived (yang dirasakan pelanggan) atas suatu pelayanan. Jika suatu kinerja tidak sesuai dengan harapan maka pelangganpun akan merasa ketidak puas, jika kinerja sesuai dengan apa yang mereka harapkan otomatis pelanggan akan merasa puas dengan apa yang diberikan namun jika kinerja sangat melebihi harapan maka pelanggan pun akan merasakan sangat puas dengan apa yang diberikan Tjiptono (2012:301).Kepuasan pelanggan dimana suatu timbal balik dari pelanggan terhadap persepsi antara perbedaan kinerja serta harapan pelanggan setelah melakukan pembelian produk atau jasa yang bersangkutan, dimana kepuasan merupakan fungsi dari persepsi atau kesan, kinerja dan harapan Tjiptono (2012:311).

Afc Futsal Center Tegaldlimo, Banyuwangi memberikan pelayanan yang bisa dilihat dari tanggapan karyawan dalam melayani pelanggan yang ingin menyewa atau memakai tempat untuk bermain futsal serta melayani segala macam keluhan yang di alami pelanggan dalam menyewa lapangan futsal dan harus memahami keingian dari pelanggan dengan tujuan pelanggan merasa puas dengan apa yang ditawarkan oleh jasa penyewaan lapangan futsal dimana kualitas pelayanan yang baik dan sesuai dengan keinginan pelanggan, pelanggan pun akan merasa puas jika kualitas pelayanan sesuai dengan keinginan dan harapan pelanggan jika pelanggan mera puas dengan kualitas pelayanan yang diberikan oleh jasa penyewaan 
lapangan futsal otomatis pelanggan akan setia terhadap perusahaan dan sebaliknya jika kualitas pelayanan yang diberikan perusahaan kurang akan menyebabkan pelanggan merasa tidak puas dengan apa yang di dapatkan serta yang di harapkan, Otomatis pelanggan akan beralih ke tempat penyewaan lapangan futsal yang lainya, masalah yang sering muncul di tempat penyewaan lapangan futsal Afc Futsal Center Tegaldlimo, Banyuwangi adalah banyaknya pelanggan yang mengeluhkan terhadap kualitas pelayanan yang diberikan kepada pelanggan setia penyewaan lapangan futsal, hal-hal yang biasanya dikeluhkan oleh para pelanggan penyewa lapangan futsal di Afc Futsal Center Tegaldlimo, Banyuwangi seperti terbatasnya fasilitas penunjang yang ada di tempat penyewaan lapangan futsal seperti kurangnya kamar mandi, wiffi untuk para pelanggan, serta hal-hal yang berkaitan dengan kesigapan karyawan dalam melayani bokingan/pesanan lapangan untuk bermain futsal pelanggan hingga keramahan yang diberikan oleh karyawan yang ada di tempat penyewaan lapangan futsal serta penanganan keluhan pengunjung kurang cepat dan tepat.

\section{Kualitas pelayanan}

Kualitas pelayanan merupakan salah satu bagian dari strategi manajemen pemasaran, kualitas pelayanan telah menjadi satu tahap faktor dominan terhadap keberhasilan suatu organisasi, atau perusahaan dengan pengembangan kualitas pelayanan didorong oleh kondisi persaingan antar perusahaan, serta kemajuan dibidang teknologi dan perekonomian, kualitas pelayanan adalah tingkat keunggulan yang diharapakan dan pengendalian atas tingkat keunggulan tersebut untuk memenuhi keinginan pelanggan Tjiptono (2011:59).

\section{Kepuasan Pelanggan}

Menurut Tjiptono (2012:301), kepuasan dipengaruhi oleh perbandingan layanan yang di pahami dengan pelayanan yang diharapkan, dan sesuai reaksi emosional jangka pendek pelanggan terhadap kinerja pelayanan tertentu.

\section{Penelitian Terdahulu}

\begin{tabular}{|c|c|c|c|c|}
\hline No & Nama & Judul Penelitian & Hasil Penelitian & Publikasi \\
\hline 1 & $\begin{array}{l}\text { Anisa Azzahra } \\
\text { Handriati, } \\
\text { Sunaryo } \\
\& \text { Vembri Noor } \\
\text { Helia (2015) }\end{array}$ & \begin{tabular}{lr} 
Analisis & kualitas \\
pelayanan & publik \\
terhadap & kepuasan \\
konsumen & dengan \\
menggunakan & metode \\
\multicolumn{2}{l}{ servperf-ipa-csi }
\end{tabular} & $\begin{array}{l}\text { Berdasarkan perhitungan CSI hasil } \\
\text { perhitungan } 71 \% \text { Atribut-atribut } \\
\text { yang perlu dilakukan perbaikan } \\
\text { dalam kategori kuadaran I terdapat } \\
4 \text { atribut yang menjadi prioritas } \\
\text { utama. }\end{array}$ & $\begin{array}{l}\text { Teknikom } \\
\text { Vol. } 21 \\
\text { No. } 4178- \\
190 \\
\text { Desember } \\
(2015)\end{array}$ \\
\hline 2 & $\begin{array}{l}\text { Shanty } \\
\text { Kusuma Dewi, } \\
\text { Dian Palupi } \\
\text { Restuputri, } \\
\text { Andri }\end{array}$ & $\begin{array}{l}\text { Analisis Kepuasan } \\
\text { Pelanggan Dengan } \\
\text { Pendekatan Metode } \\
\text { Customer Satisfaction } \\
\text { Index dan Importance }\end{array}$ & $\begin{array}{l}\text { hasil perhitungan CSI didapatkan } \\
\text { nilai sebesar } 68,27 \% \text {, Hasil dari } \\
\text { pemetaan tingkat kepentingan dan } \\
\text { kinerja dari Taman Rekreasi } \\
\text { Sengkaling didapatkan tujuh }\end{array}$ & $\begin{array}{l}\text { Seminar } \\
\text { Teknologi } \\
\text { dan } \\
\text { Rekayasa } \\
\text { (SENTRA }\end{array}$ \\
\hline
\end{tabular}


Sujik Nor Afandi, Akhmad Suharto, dan Jekti Rahayu

\begin{tabular}{|c|c|c|c|c|}
\hline & $\begin{array}{l}\text { Sulaksmi } \\
(2015)\end{array}$ & $\begin{array}{l}\text { Performance Analysis } \\
\text { pada Taman Rekreasi } \\
\text { Sangkaling Malang }\end{array}$ & $\begin{array}{l}\text { atribut yang masuk dalam prioritas } \\
\text { utama ada } 8 \text { yang harus diperbaiki. }\end{array}$ & $\begin{array}{l}1,206- \\
222 . \\
(2015)\end{array}$ \\
\hline 3 & $\begin{array}{l}\text { Moh. Hilman } \\
\text { Kamaluddin, } \\
\text { Dwi Fatrianto } \\
\text { Suyatno (2017) }\end{array}$ & $\begin{array}{l}\text { Analisis Kepuasan } \\
\text { Pengguna Sitem } \\
\text { Akademik Terpadu } \\
\text { (SIAKADU) } \\
\text { Universitas Negri } \\
\text { Surabaya. }\end{array}$ & $\begin{array}{l}\text { Berdasarkan kriteria } \\
\text { kepuasan } \text { (CSI), } \\
\text { Surabaya SIAKADitas }\end{array} \begin{array}{l}\text { Negeri } \\
\text { 76.22\%. hasil IPA pada kuadran I } \\
\text { terdapat enam atribut yang harus } \\
\text { menjadi perhatian utama }\end{array}$ & $\begin{array}{l}\text { Jurnal } \\
\text { Pendidika } \\
\text { n Tata } \\
\text { Niaga } 1 \\
\text { april } \\
(2017)\end{array}$ \\
\hline 4 & $\begin{array}{l}\text { Mutiara Laila } \\
\text { Ramadhani,Yu } \\
\text { dian Tri Asdi, } \\
\text { Hazmir A } \\
\text { Yoza (2019) }\end{array}$ & $\begin{array}{l}\text { Analisis Tingkat } \\
\text { Kepuasan Pasien } \\
\text { Terhadap Pelayanan } \\
\text { Poliklinik Embun Pagi } \\
\text { RSUD DR.M } \\
\text { DJAMIL Padang } \\
\text { dengan Metode IPA }\end{array}$ & $\begin{array}{l}\text { Berdasarkan nilai CSI sebesar } \\
78,14 \% \text {. Berdasarkan hasil IPA, } \\
\text { dapat diketahui indikator-indikator } \\
\text { yang harus dibenahi yaitu ada } 9 \\
\text { atribut yang menjadi perhatian. }\end{array}$ & $\begin{array}{l}\text { Jurnal } \\
\text { Matematik } \\
\text { a } \\
\text { UNAND, } \\
4(3), 95 \text {. } \\
(2019)\end{array}$ \\
\hline 5 & $\begin{array}{l}\text { Jekti Rahayu } \\
(2016)\end{array}$ & $\begin{array}{l}\text { Analisis Dampak } \\
\text { Kualitas Pelayanan } \\
\text { dan Harga Terhadap } \\
\text { Loyalitas Konsumen } \\
\text { Melalui Kepuasan } \\
\text { Konsumen (Studi } \\
\text { Pada Konsumen PT. } \\
\text { Rahayu Citra Mandiri } \\
\text { Jember) }\end{array}$ & $\begin{array}{l}\text { Hasil pengujian } \\
\text { pelayanan, berpengaruh positif dan } \\
\text { signifikan terhadap kepuasan } \\
\text { pelanggan., Hasil pengujian } \\
\text { membuktikan kualitas pelayanan, } \\
\text { berpengaruh positif dan signifikan } \\
\text { terhadap loyalitas pelanggan. }\end{array}$ & $\begin{array}{l}\text { Jurnal } \\
\text { Universita } \\
\text { s } \\
\text { Muhamma } \\
\text { diyah } \\
\text { Jember,1- } \\
13(2016)\end{array}$ \\
\hline
\end{tabular}

Sumber : Penelitian Terdahulu 2021

Metodologi

Desain Penelitian

Desain penelitian yang digunakan adalah kuantitatif deskriptif dengan menggunakan metode CSI dan IPA untuk mengukur kepuasan pelanggan pada Afc Futsal Center Tegaldlimo.

\section{Populasi dan Sempel}

Populasi pada peneliian ini adalah seluruh pengunjung atau pelanggan Afc Futsal Center. Sempel adalah supset dari populasi, yang terdiri dari beberapa anggota populasi Sempel dalam penelitian ini adalah sebagian pengunjung atau pengguna lapangan futsal di Afc Futsal 
Center sebanyak 89 responden, teknik Nonprobability sampling yang diambil pada penelitian ini yaitu convenience sampling,

\section{Definisi Operasional Variabel}

a. Variabel Kualitas Pelayanan

Menurut Parasuraman, et al., dalam Tjiptono (2011: 347) Dalam mengukur kualitas pelayanan terdapat indikator-indikator yang bisa digunakan, yaitu :

Tangibel/bukti fisik meliputi Tata letak lapangan afc futsal center yang nyaman, Terdapat loker atau tempat penyimpanan barang yang aman untuk pelanggan, Ruangan pada Afc Futsal Center selalu dijaga kebersihannya, Kelengkapan fasilitas di Afc Futsal Center cukup lengkap seperti mushola dan parkir, toilet, bola, penerangan lampu, Tempat duduk yang nyaman.

Reability/kehandalan meliputi Fasilitas yang disediakan sesuai dengan iklan depan afc futsal center, Kesigapan karyawan dalam melayani bokingan/pesanan lapangan untuk bermain, Karyawan menyelesaikan pekerjaan sesuai dengan permintaan pelanggan ,Kemampuan afc futsal center untuk melayani jasa penyewaan lapangan disetiap kalangan Responsive/daya tanggap meliputi Karyawan melayani pelanggan sesuai dengan urutan kedatangan pelanggan, Kecepatan karyawan pada afc futsal center dalam mengatasi keluhan dari pelanggan, Karyawan selalu siap ketika dimintai bantuan oleh pelanggan

Assurance/jaminan meliputi Keramahan karyawan terhadap pelanggan yang ada di tempat penyewaan lapangan futsal, Kesopanan karyawan terhadap pelanggan Afc Futsal Center, Jaminan keamanan serta ketenangan pelanggan pada saat berada di afc futsal center

Emphaty/empati meliputi hubungan komunikasi antara karyawan dan pelanggan secara baik, Perhatian pihak afc futsal center atau karyawan secara individu terhadap pelanggan, Karyawan memberikan respon yang baik dalam menerima suatu kritikan dan saran dari pelanggan, Karyawan memahami keinginan serta kebutuhan dari pengunjung

b. Variabel Kepuasan Pelanggan

Keputusan pembelian adalah tingkat perasaan seseorang setelah membandingkan suatu hasil yang sudah dirasakan dibandingkan dengan harapan yang diukur melalui indikator.

1. Kesesuaian harapan

2. Minat untuk berkunjung Kembali

3. Kesediaan untuk merekomendasi

\section{Teknik Pengumpulan Data}

\section{a. Kuisioner}

Menurut Sugiyono (2011), kuesioner merupakan teknik pengumpulan data yang dilakukan dengan cara memberi seperangkat pertanyaan atau pernyataan tertulis kepada responden untuk dijawab. Kuesioner dapat berupa pertanyaan atau pernyataan tertutup, terbuka atau campuran. 
Sujik Nor Afandi, Akhmad Suharto, dan Jekti Rahayu

b. Observasi

Observasi dalam penelitian ini yaitu dengan mengamati objek secara langsung di Afc Futsal Center Tegaldlimo, Banyuwangi.

\section{Customer Satisfaction Index}

Metode Customer Satisfaction Index (CSI) atau yang lebih dikenal dengan indeks kepuasan pelanggan merupakan suatu indeks yang menentukan tingkat kepuasan pelanggan secara menyeluruh dengan melakukan pendekatan yang memperhitungkan tingkat kepentingan dan kinerja dari atribut-atribut yang diukur.

a. Menentukan Mean Important Score (MIS) dan Mean Satisfaction Score (MSS).

$$
\begin{aligned}
\text { MIS } & =\frac{\sum_{i=1}^{n} y_{i}}{\mathrm{n}} \\
\text { MSS } & =\frac{\sum_{i=1}^{n} x_{i}}{\mathrm{n}}
\end{aligned}
$$

Dimana :

$\mathrm{n} \quad=$ jumlah responden

$Y_{i} \quad=$ nilai kepentingan atribut

$\bar{X}_{\bar{f}} \quad=$ nilai kinerja atribut ke-i

b. Membuat Weight Factors (WF). Bobot ini merupakan persentase nilai MIS per atribut terhadap soal MIS seluruh atribut

$$
W F i=\frac{M^{2} I_{i}}{\sum_{i=1}^{p} M S I_{i}} X 100 \%
$$

Dimana :

$\mathrm{P} \quad=$ jumlah atribut kepentingan

I = atribut bauran pemasaran ke-i

c. Membuat Weigh Score (WS) Bobot ini merupakan perkalian antara Weigh Factor (WF) dengan rata-rata tingkat kepuasan Mean Statsfaction Score (MSS) Dimana :

$\mathrm{i} \quad=$ atribut bauran pemasaran ke-i

$$
\begin{aligned}
& W S_{i}=W F_{i} X M S S_{I} \\
& C S I=\frac{\sum_{i=}^{p} W S_{i}}{5} X 100 \%
\end{aligned}
$$

d. Menentukan Customer Statisfaction Indek (CSI)

Menurut irawan,(2004), metode customer statisfaction index (CSI) terdapat kriteria untuk mengetahui tingkat kepuasan pelanggan terhadap kualitas pelayanan sebagai berikut :

Tabel 1 Customer Statisfaction Index

\begin{tabular}{cc}
\hline Nilai Indeks $(\%)$ & Kriteris Customer statisfaction Index \\
\hline $81,00-100,00$ & Sangat Puas \\
$66,00-80,99$ & Puas \\
$51,00-65,99$ & Cukup Puas
\end{tabular}




$$
\begin{array}{cc}
35,00-50,99 & \text { Kurang Puas } \\
0,00-34,99 & \text { Tidak Puas }
\end{array}
$$

Sumber : Irawan, 2004

\section{Importance Performance Analisis (IPA)}

Dalam metode IPA atribut-atribut yang diteliti akan dipetakan kedalam suatu diagram kartesius yang terbagi dalam empat wilayah atau kuadran, yaitu prioritas utama (I), pertahanan prestasi (II), priorita $\bar{\xi}$ rendah (III), berlebihan (IV).

\begin{tabular}{|c|c|}
\hline $\begin{array}{c}\text { Kuadran I } \\
\text { Prioritas Utama }\end{array}$ & $\begin{array}{c}\text { Kuadran II } \\
\text { Pertahankan Prestasi }\end{array}$ \\
\hline $\begin{array}{c}\text { Kuadran III } \\
\text { Prioritas Rendah }\end{array}$ & $\begin{array}{c}\text { Kuadran IV } \\
\text { Berlebihan }\end{array}$ \\
\hline
\end{tabular}

Gambar 1 Diagram Kartesius

\section{Hasil dan Pembahasan}

Analisis Teknik Kepuasan Responden Dengan Menggunakan CSI

\begin{tabular}{|c|c|c|c|c|c|}
\hline No & ATRIBUT & MSS & $M I S$ & $W F$ & WS \\
\hline 1 & Tata letak lapangan Afc Futsal Center yang nyaman & 3,07 & 3,39 & 5,12 & 15,70 \\
\hline 2 & $\begin{array}{l}\text { Terdapat loker atau tempat penyimpanan barang yang } \\
\text { aman untuk pelanggan }\end{array}$ & 3,04 & 3,35 & 5,05 & 15,38 \\
\hline 3 & $\begin{array}{l}\text { Ruangan pada Afc Futsal Center selalu dijaga } \\
\text { kebersihannya }\end{array}$ & 2,67 & 3,29 & 4,97 & 13,28 \\
\hline 4 & $\begin{array}{l}\text { Kelengkapan fasilitas di afc futsal center cukup } \\
\text { lengkap seperti mushola dan parkir serta toilet,bola, } \\
\text { penerangan lampu }\end{array}$ & 2,91 & 3,43 & 5,17 & 15,04 \\
\hline 5 & Tempat duduk yang nyaman & 2,90 & 3,45 & 5,20 & 15,08 \\
\hline 6 & $\begin{array}{l}\text { Fasilitas yang disediakan sesuai dengan iklan depan } \\
\text { afc futsal center }\end{array}$ & 3,43 & 3,29 & 4,97 & 17,02 \\
\hline 7 & 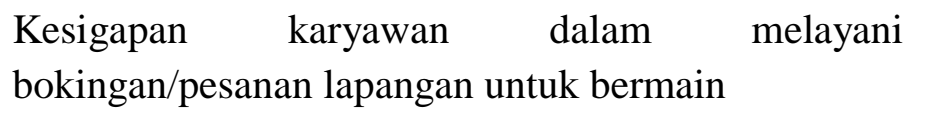 & 2,75 & 3,80 & 5,73 & 15,77 \\
\hline 8 & $\begin{array}{l}\text { Karyawan menyelesaikan pekerjaan sesuai dengan } \\
\text { permintaan pelanggan }\end{array}$ & 3,07 & 3,89 & 5,86 & 17,99 \\
\hline 9 & $\begin{array}{l}\text { Kemampuan afc futsal center untuk melayani jasa } \\
\text { penyewaan lapangan disetiap kalangan }\end{array}$ & 3,38 & 3,27 & 4,93 & 16,68 \\
\hline
\end{tabular}

Tabel 3 Hasil Analisis Customer Satisfaction Index (CSI) 
Sujik Nor Afandi, Akhmad Suharto, dan Jekti Rahayu

\begin{tabular}{|c|c|c|c|c|}
\hline $\begin{array}{l}\text { Karyawan melayani pelanggan sesuai dengan urutan } \\
\text { kedatangan pelanggan }\end{array}$ & 2,91 & 3,36 & 5,07 & 14,75 \\
\hline $\begin{array}{l}\text { Kecepatan karyawan pada afc futsal center dalam } \\
\text { mengatasi keluhan dari pelanggan }\end{array}$ & 2,65 & 3,69 & 5,56 & 14,74 \\
\hline $\begin{array}{l}\text { Karyawan selalu siap ketika dimintai bantuan oleh } \\
\text { pelanggan }\end{array}$ & 3,08 & 3,55 & 5,36 & 16,49 \\
\hline $\begin{array}{l}\text { Keramahan karyawan terhadap pelanggan yang ada di } \\
\text { tempat penyewaan lapangan futsal }\end{array}$ & 2,58 & 3,78 & 5,69 & 14,72 \\
\hline Kesopanan karyawan terhadap pelanggan & 2,89 & 3,36 & 5,07 & 14,63 \\
\hline $\begin{array}{l}\text { Jaminan keamanan serta ketenangan pelanggan pada } \\
\text { saat berada di afc futsal center }\end{array}$ & 2,84 & 3,44 & 5,19 & 14,74 \\
\hline $\begin{array}{l}\text { hubungan komunikasi antara karyawan dan } \\
\text { pelanggan secara baik }\end{array}$ & 3,07 & 3,85 & 5,81 & 17,83 \\
\hline $\begin{array}{l}\text { Perhatian pihak afc futsal center atau karyawan secara } \\
\text { individu terhadap pelanggan }\end{array}$ & 2,70 & 3,31 & 5,00 & 13,48 \\
\hline $\begin{array}{l}\text { Karyawan memberikan respon yang baik dalam } \\
\text { menerima suatu kritikan dan saran dari pelanggan }\end{array}$ & 2,72 & 3,43 & 5,17 & 14,05 \\
\hline $\begin{array}{l}\text { Karyawan memenuhi keinginan serta kebutuhan dari } \\
\text { pengunjung }\end{array}$ & 2,80 & 3,38 & 5,10 & 14,26 \\
\hline Total & 55,46 & 66,31 & 100 & 291,62 \\
\hline
\end{tabular}

Sumber : Data Lampiran 3, 2021

Analisis Teknik Kepuasan Responden Dengan Menggunakan IPA

Tabel 4. Hasil Analisis Importance Performance Analisis (IPA)

\begin{tabular}{|c|c|c|c|}
\hline KODE & ATRIBUT & KINERJA & KEPENTINGAN \\
\hline 1 & $\begin{array}{l}\text { Tata letak lapangan Afc Futsal Center yang } \\
\text { nyaman }\end{array}$ & 3,07 & 3,39 \\
\hline 2 & $\begin{array}{l}\text { Terdapat loker atau tempat penyimpanan barang } \\
\text { yang aman untuk pelanggan }\end{array}$ & 3,04 & 3,35 \\
\hline 3 & $\begin{array}{l}\text { Ruangan pada Afc Futsal Center selalu dijaga } \\
\text { kebersihannya }\end{array}$ & 2,67 & 3,29 \\
\hline 4 & $\begin{array}{l}\text { Kelengkapan fasilitas di afc futsal center cukup } \\
\text { lengkap seperti mushola dan parkir serta } \\
\text { toilet,bola, penerangan lampu }\end{array}$ & 2,91 & 3,43 \\
\hline
\end{tabular}


5 Tempat duduk yang nyaman

6 Fasilitas yang disediakan sesuai dengan iklan depan afc futsal center

7 Kesigapan karyawan dalam melayani bokingan/pesanan lapangan untuk bermain

8 Karyawan menyelesaikan pekerjaan sesuai dengan permintaan pelanggan

9 Kemampuan afc futsal center untuk melayani jasa penyewaan lapangan disetiap kalangan

Karyawan melayani pelanggan sesuai dengan urutan kedatangan pelanggan

Kecepatan karyawan pada afc futsal center dalam mengatasi keluhan dari pelanggan

Karyawan selalu siap ketika dimintai bantuan oleh pelanggan

Keramahan karyawan terhadap pelanggan yang ada di tempat penyewaan lapangan futsal

14 Kesopanan karyawan terhadap pelanggan

Jaminan keamanan serta ketenangan pelanggan pada saat berada di afc futsal center hubungan komunikasi antara karyawan dan pelanggan secara baik

Perhatian pihak afc futsal center atau karyawan secara individu terhadap pelanggan

Karyawan memberikan respon yang baik dalam menerima suatu kritikan dan saran dari pelanggan

\section{RATA-RATA}

Sumber : Data Lampiran 3 Kuisioner, 2021

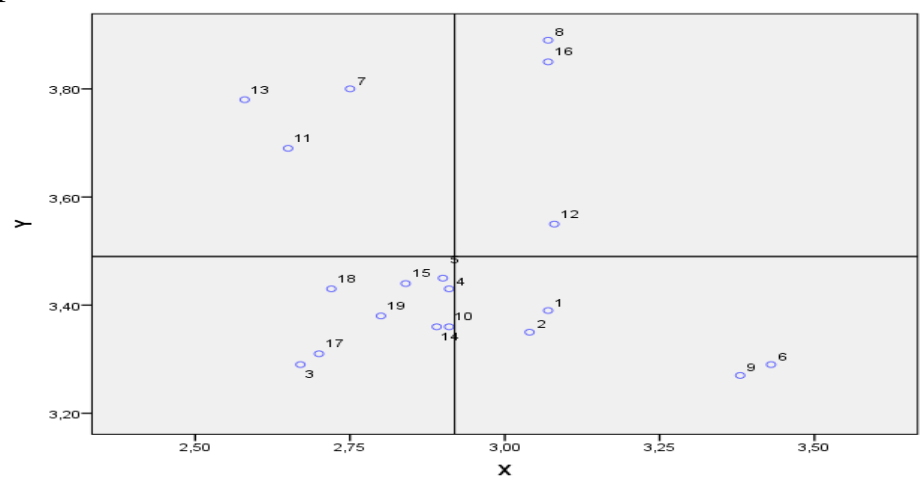


Gambar 2 Diagram Kartisius Hasil Pengelolaan Metode IPA Berdasarkan perhitungan dengan menggunakan metode Customer Statisfaction Index tingkat kepuasan pelanggan Afc Futsal Center Tegaldlimo sebesar $(58,32 \%$.) katagori cukup puas. Kuadran I (Prioritas Utama) Kesigapan karyawan dalam melayani bokingan/pesanan lapangan untuk bermain (atribut 7) Kesigapan karyawan dalam melayani bokingan lapangan oleh pelanggan merupakan hal yang sangat penting oleh sebab itu karyawan Afc Futsal Center diharapkan selalu sigap untuk melayani suatu penyewaan lapangan dan selalu siap ditempat penyewaan lapangan futsal dan di WA., Kecepatan karyawan pada Afc Futsal Center dalam mengatasi keluhan dari pelanggan (atribut 11). Kecepatan karyawan pada afc futsal center dalam mengatasi keluhan dari pelanggan merupakan suatu hal yang penting untuk diperhatikan oleh pengelola Afc Futsal Center, kecepatan dalam mengatasi keluhan pelanggan dapat menimbulkan suatu kesan yang baik dalam hal kualitas pelayanan, Keramahan karyawan terhadap pelanggan yang ada di tempat penyewaan lapangan futsal (atribut 13). Keramahan karyawan terhadap pelanggan merupakan suatu hal yang penting untuk diperhatikan dimana karyawan yang ramah kepada pelanggan dan tutur bicara yang manis akan menimbulkan kedekatan baik di dalam dan diluar penyewaan lapangan futsal. Strategi yang bisa digunakan yaitu dengan menjaga tutur kata yang manis kepada setiap pelanggan dan pendekatan kepada pelanggan secara menyeluruh

Kuadran II Karyawan menyelesaikan pekerjaan sesuai dengan permintaan pelanggan (atribut 8) Permintaan pelanggan adalah hal yang harus dipenuhi oleh pengelola Afc Futsal Center agar pelanggan merasa puas selama berada di tempat penyewaan lapangan futsal seperti pergantian bola, Karyawan selalu siap ketika dimintai bantuan oleh pelanggan (atribut 12) Karyawan harus selalu siap jika pelanggan membutuhkan bantuan mengenai fasilitas atau sarana dan prasarana yang ada ditempat penyewaan lapangan futsal, hubungan komunikasi antara karyawan dan pelanggan secara baik (atrbut 16) komunikasi karyawan dan pelanggan harus dipertahankan, hal ini karena cukup kebanyak pelanggan melakukan penyewaan dengan menggunakan wa sebagi alat untuk memesan lapangan dan disitulah timbul suatu komunikasi antara pelanggan dan pengelola.

Kuadran III Ruangan pada Afc Futsal Center selalu dijaga kebersihannya (atribut 3) Karyawan harus menjaga kebersihan ruangan penyewaan lapangan futsal agar pelanggan merasa nyaman pada saat berada di penyewaan lapangan futsal Afc Futsal Center, Kelengkapan fasilitas di afc futsal center cukup lengkap seperti mushola dan parkir serta toilet,bola, penerangan lampu (atribut 4) Atribut ini dinilai kurang penting oleh pelanggan namun meskipun demikian karyawan Afc Futsal Center harus seslau meningkatkan kualitas pelayanan agar pelanggan merasa puas dengan fasilitas yang ada Tempat duduk yang nyaman (atribut 5) Atribut ini dianggap kurang penting oleh pelanggan meskipun demikian tempat duduk yang nyaman bisa menjadi penunjang kepuasan pelanggan, Karyawan melayani pelanggan sesuai dengan urutan kedatangan pelanggan (atribut 10) Melayani urutan 
kedatangan pelanggan pada saat memesan lapangan baik online maupun offline yang terlebih dahulu memesan lapangan akan dilayani sesuai dengan urutan pada saat memesan lapangan, Kesopanan karyawan terhadap pelanggan (atribut 14) Sikap sopan haruslah dimiliki oleh karyawan Afc Futsal Center terhadap pelanggan dimana akan membuat pelanggan merasakan kesenangan karena diperlakukan dengan baik., Jaminan keamanan serta ketenangan pelanggan pada saat berada di Afc Futsal Center (atribut 15) Jaminan keamanan haruslah dimiliki oleh tempat wisata agar pelanggan pun merasa nyaman serta terjaga selama berada di penyewaan lapangan futsal, Perhatian pihak afc futsal center atau karyawan secara individu terhadap pelanggan (atribut 17) Tak hanya karyawan tetapi pemilik futsalan pun harus membaur pelanggan dan bersikap baik dan ramah kepada pelanggan agar pelanggan merasa dihargai dan dihormati, Karyawan memberikan respon yang baik dalam menerima suatu kritikan dan saran dari pelanggan. (atribut 18) karyawan merespon semua kritik dan saran dari pelanggan yang ada dipenyewaan lapangan futsal agar segera di perbaiki agar pelanggan merasa lebih nyaman lagi, Karyawan memenuhi keinginan serta kebutuhan dari pengunjung atau pelangan (atribut 19) Karyawan harus paham apa saja yang dibutuhkan oleh pelanggan dan karyawan haruslah melayani pelanggan dengan sepenuh hati tanpa membeda bedakan pelanggan yang satu dengan pelanggan yang lainya

Kuandran IV Tata letak lapangan Afc Futsal Center yang nyaman (atribut 1) Atribut ini dianggap terlalu berlebihan dalam pelaksanaanya, jarangnya pelanggan memperhatikan letak lapangan futsal saat menyewa lapangan futsal, Terdapat loker atau tempat penyimpanan barang yang aman untuk pelanggan (atribut 2) Atribut ini dianggap terelu berlebihan dalam pelaksanaanya, karena jarangnya pelanggan yang memakai loker untuk menyimpan barang pelanggan, Fasilitas yang disediakan sesuai dengan iklan depan Afc Futsal Center (atribut 6) Atribut ini dianggap terlelu berlebihan dalam pelaksanaanya, dalam pembuatan poster yang ditujukan untuk menarik pelanggan harus sesuai dengan kondisi yang ada, dimana atribut ini jarang ditanyakan oleh responden apakah sudah sesuai apa belum dan dirasa tidak terlalu penting .Kemampuan afc futsal center untuk melayani jasa penyewaan lapangan disetiap kalangan (atribut 9) Atribut ini dianggap terlalu berlebihan dalam pelaksanaanya, hal itu karena jarangnya pelanggan yang menanyakan tentang pelayanan jasa yang berbeda disetiap kalangan, dimana Afc Futsal Center selalu melayani pelanggan disetiap kalangan dengan sama adil

\section{Kesimpulan}

Berdasarkan hasil dari analisis (CSI) diperoleh hasil 58,32\%. Berdasarkan analisis (IPA), diperoleh 3 atribut di kuadran I, dan 3 atribut di kuadran II, 9 atribut di kuadran III, 4 atribut di kuadran IV. 
Sujik Nor Afandi, Akhmad Suharto, dan Jekti Rahayu

\section{Bibliografi}

Dewi, S. K., Restuputri, D. P., \& Sulaksmi, A. (2015). Analisis Tingkat Kepuasan Pelanggan dengan Menggunakan Metode Customer Satisfaction Index dan Impotance Performance Analysis. Seminar Teknologi Dan Rekayasa (SENTRA), 1, 206-222.

Fandy, Tjiptono. (2011). Service Management Mewujudkan Layanan Prima. Edisi 2. Yogyakarta: Andi

Handriati, A. A., Sunaryo, S., \& Helia, V. N. (2015). Analisis Kualitas Pelayanan Publik Terhadap Kepuasan Konsumen. Teknikom, 21(4). https://doi.org/10.20885/teknoin.vol21.iss4.art4

Irawan, 2004 Irawan, H. 2004. Indonesian Customer Satisfaction: Membedah Strategi Kepuasan Pelanggan Merek Pemenang ICSA. Jakarta : PT Alex Media Komputindo

Kotler dan Keller, (2012:27). Manajemen Pemasaran edisi ketiga belas jilid 1 dan 2 dialih bahasakan oleh Bob Sabran, Jakarta: Erlangga

Kamaluddin, Hilman (2017). Universitas Negeri Surabaya. Jurnal Pendidikan Tata Niaga, 1(April). https://doi.org/10.1074/jbc.271.41.25173

Rahayu, Jekti, (2016), Analisis Dampak Kualitas Pelayanan Dan Harga Terhadap Loyalitas Konsumen Melalui Kepuasan Konsumen, Jurnal Universitas Muhammadiyah Jember, $1-13$

Ramadhany, M. L., Asdi, Y., \& Yozza, H. (2019). Analisis Tingkat Kepuasan Pasien terhadap Pelayanan Poliklinik Embun Pagi RSUP M. Djamil Padang dengan Metode Importance Performance Analysis. Jurnal Matematika UNAND, 4(3), 95. https://doi.org/10.25077/jmu.4.3.95-106.2015

Sugiyono (2011). Metode Penelitian Kuantitatif Kualitatif DAN R\&D (cetakan ke- 14). Bandung: Alfabeta.

Tjiptono, Fandy., 2012, Pemasaran Jasa. Yogjakarta: Penerbit Andi 